\title{
NOTAS SOBRE Leptodeira annulata DE RORAIMA I. VARIAÇÕES NO NÚMERO DE ESCAMAS EM POPULAÇÕES DE MATA E LAVRADO (SERPENTES: Colubridae)
}

\begin{abstract}
Sebastião Pereira do Nascimento
RESUMO - Análises taxonômicas foram feitas, através de contagem de escamas dorsais, ventrais e subcaudais em 73 exemplares de Leptodeira annulata, procedentes de quatro localidades de Roraima, extremo norte da Amazônia brasileira, considerando as duas feições características da região: mata e lavrado. As análises estatísticas demonstraram que as variações no número de escamas de L. annulata não diferem significativamente ao nível de 5\%. Isso permite concluir que as populações observadas se definem de forma homogênea entre as localidades de mata e lavrado, e que as amostras analisadas foram retiradas da mesma população estatística.
\end{abstract}

Palavras-chave: Leptodeira annulata; Roraima; Amazônia.

ABSTRACT - Taxonomic analysis were done, through counting of dorsal, ventral and subcaudal scales in a sample of 73 individuals of Leptodeira annulata, from four localities of Roraima, in the northermost part of Brazilian Amazonia, considering the two aspects of the region: forest and lavrado field. The statistic analysis showed that variation in the number of scales of $L$. annulata don't differ significantly to the level of 5\%. This suggest that the populations observed are uniform between the localities of forest and lavrado field, and that the sample analised were taken from the same statistic population.

Key words: Leptodeira annulata; Roraima; Amazônia.

$\overline{1}$ Museu Integrado de Roraima - Setor de Zoologia

Bol. Mus. Int. de Roraima, Boa Vista, 3 (1): 20-35, jul. 1995. 


\section{INTRODUÇÃO}

Leptodeira annulata é uma cobra comum na região neotropical. Em sua ampla área de ocorrência foram descritas variações no número de escamas entre populações de regiões geograficamente distantes e fisionomicamente distintas (Duellmam, 1958). Entretanto, faltam informações sobre essas variações entre indivíduos de populações locais associadas aos tipos regionais de vegetação, como áreas abertas e fechadas, por exemplo. Isto é essencial na caracterização de populações locais, a unidade básica do processo evolutivo (Vanzolini, 1993).

Constituindo uma das mais freqüentes espécies de Roraima, obteve-se um razoável número de exemplares desta cobra, que permitiu empreender uma análise preliminar destes caracteres entre indivíduos coletados em quatro localidades da região. Como estas localidades estão situadas em regiões com vegetação distinta - mata e lavrado, escolhidas a propósito, isto implica também, em última análise, verificar se as populações de L. annulata estão ecologicamente isoladas ou não.

As hipóteses nulas testadas neste exercício são que as localidades não diferem significativamente entre si com relação às variações observadas no número de escamas, ao nível de P>0,05 de significância. Os caracteres analisados foram: número de fileiras de escamas dorsais, número de escamas ventrais e número de subcaudais.

\section{Categoria sistemática e variação no número de escamas (Dados da literatura)}

Em sua revisão sistemática do gênero Leptodeira, Duellman (1958) reconheceu cinco subespécies para L. annulata. A subespécie assinalada para a região de Roraima é annulata (Duellman, 1958; Cunha \& Nascimento, 1980), porém isso é confuso. No decorrer deste exercício usa-se apenas a grafia específica L. annulata, já que não há intenção de discorrer sobre o nível subespecífico desta cobra.

O holótipo da espécie L. annulata, descrito por Linnaeus (1758)depositado no Zoologische Institutionem Uppsala - como Coluber annulatus, tem como localidade tipo "América" em seu Systema Naturae. É um macho com 190 escamas ventrais e 19 fileiras de dorsais (Duellman, 1958).

$\mathrm{Na}$ descrição da subespécie Leptodeira annulata Duellman examinou 12 exemplares procedentes do baixo rio Amazonas, Pará, sem citar a localidade. Os exemplares apresentaram 180-200 escamas ventrais nos machos e 174-199 nas fêmeas: subcaudais em 74-102 nos machos e 72-100 nas fêmeas. Escamas dorsais em 19 fileiras, alguns de 17 ou 21, reduzindo para 13 e 15 fileiras, alguns em 11 e 17. Entretanto, o número de exemplares examinados foi baixo, 6 machos e 6 fêmeas, difícil de saber a normalidade no número de fileiras de escamas dorsais e número de ventrais e subcaudais daquela região.

Bol. Mus. Int. de Roraima, Boa Vista, 3 (1): 20-35, jul. 1995. 
$\mathrm{Na}$ região leste do Pará, os exemplares estudados por Cunha \& Nascimento (1993, edição revisada de 1978) apresentaram 19 e 21 fileiras de escamas dorsais, com redução - não diz para quanto reduz: 186-198 ventrais e 83-102 subcaudais, com base em 24 exemplares coletados.

Nos exemplares da Guiana Francesa analisados por Chippaux (1987), as escamas dorsais apresentaram 19, 21 e 23 (normalmente 19 e 21 fileiras): ventrais em 190-203, com dimorfismo sexual; mais de 196 ventrais nos machos e menos de 198 nas fêmeas. Subcaudais 82-103. Foram analisados 21 exemplares. As dorsais apresentaram redução, não citando o número de fileiras. Os 4 exemplares analisados por Gasc \& Rodrigues (1980), na Guiana Francesa, apresentaram 21 fileiras de dorsais: ventrais 190-201; subcaudais $74-103$.

Na Venezuela os exemplares estudados por Roze (1966) apresentaram 17, 19 e 21 fileiras de escamas dorsais (normalmente 19), com reduções não diz para quanto reduz. Ventrais em 174-200; subcaudais 72-102. Foram analisados 5 exemplares.

TABELA 1. Fileiras de escamas dorsais e número de escamas ventrais e subcaudais de Leptodeira annulata: Dados de literatura e do presente trabalho.

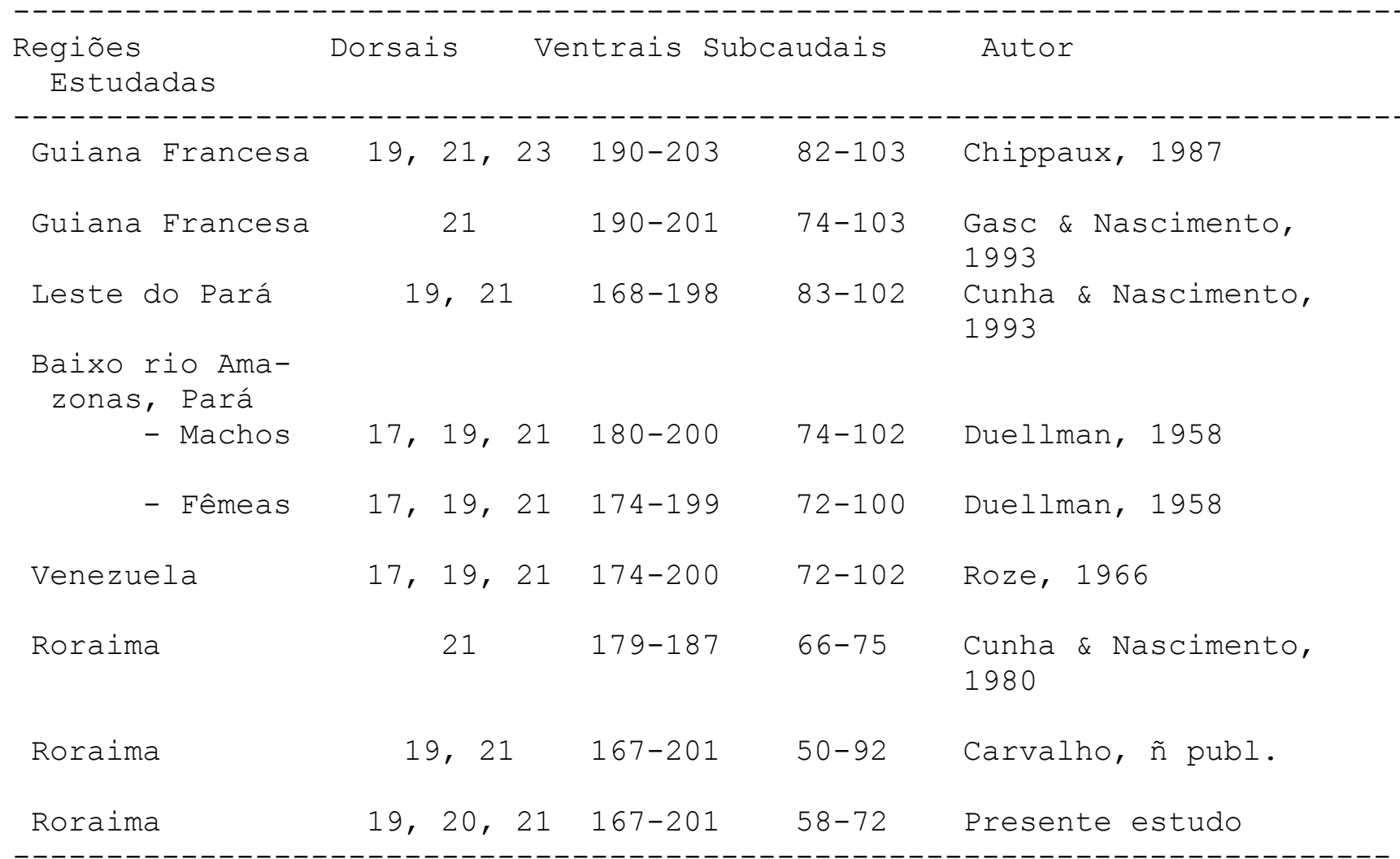

Bol. Mus. Int. de Roraima, Boa Vista, 3 (1): 20-35, jul. 1995. 
Nos 7 exemplares coletados em Roraima por Cunha \& Nascimento (1980), as escamas não dorsais são em 21 fileiras - não diz para quanto reduz: as ventrais em 179-187; as subcaudais 66-75 escamas. Outros 23 exemplares da região de Roraima apresentam as escamas dorsais em 19 ou 21 fileiras, reduzindo para 15 ou 17 na região anal: ventrais 167-201; subcaudais 50-92 (Carvalho, 1994 - com. pess.).

\section{Descrição e distribuição geográfica}

Leptodeira annulata tem a cabeça distinta do corpo, olho grande com pupila vertical, internasais mais curtos que os pré-frontais, frontal mais longa que larga, nasais divididas, loreais um pouco mais largas que altas, 2 post-oculares, supralabiais 8, a $4^{\underline{a}}$ e $5^{\underline{a}}$ tocando 0 olho, 10 ou 11 infralabiais. Escamas dorsais lisas, com fossetas apicilares, em 17, 19, 21 ou 23 fileiras (normalmente 19 ou 21), com redução para 11, 13, 14, 15, 16 ou 17 fileiras na região anal (normalmente 15 ou 17). Ventrais: 167203; subcaudais:58-103; anal dividida.

O nome comum desta tímida e inofensiva cobra é jararaca (falsa), em virtude da confusão que o povo faz com a verdadeira (gênero Bothrops), embora sejam muito diferentes uma da outra.

A distribuição de L. annulata (subesp. annulata) é ampla. Ocorre desde o leste dos Andes, no Equador, Peru, Venezuela, Bolívia, Colômbia, estendendo-se até a Guiana Francesa e República Cooperativista da Guiana. No Brasil ocorre por toda a Amazônia, cerrado do Brasil Central e Mata Atlântica, até São Paulo (Peters \& Orejas-Miranda, 1986; Roze, 1966; Cunha \& Nascimento, 1993).

\section{Material examinado de Roraima e localidades amostradas}

- material examinado está exposto no Museu Integrado de Roraima (MIRR), da Secretaria de Educação, RR. Só foram examinados aqueles exemplares onde a localidade não deixou margem de dúvidas.

Os exemplares analisados procedem de quatro regiões com coberturas vegetais distintas - mata e lavrado (descrição detalhada da região em Vanzolini \& Carvalho, 1991 - Figura 1: Mapa; pág. 35).

Lavrado (áreas abertas): Boa Vista, 25 exemplares $\left(02^{\circ} 49^{\prime} \mathrm{N}, 60^{\circ} 30^{\prime} \mathrm{W}\right)$ e maloca indígena Mangueira, 11 exemplares $\left(03^{\circ} 20^{\prime} \mathrm{N}, 61^{\circ} 24^{\prime} \mathrm{W}\right)$;

Mata (áreas fechadas): Vila Pacaraima, 16 exemplares (BV-8; $04^{\circ} 29^{\prime} \mathrm{N}, 61^{\circ}$ 10' W) e Estação Ecológica de Maracá, IBAMA, 21 exemplares (ilha de Maracá: $\left.03^{\circ} 24^{\prime} \mathrm{N}, 61^{\circ} 38^{\prime} \mathrm{W}\right)$.

Bol. Mus. Int. de Roraima, Boa Vista, 3 (1): 20-35, jul. 1995. 
Para fins práticos considerou-se que cada localidade representa uma população de L. annulata onde os exemplares retirados constituem amostras de uma população local. População local é aqui definida pragmaticamente como uma entidade abstrata representada por uma amostra real de uma localidade específica (Vanzolini, 1993).

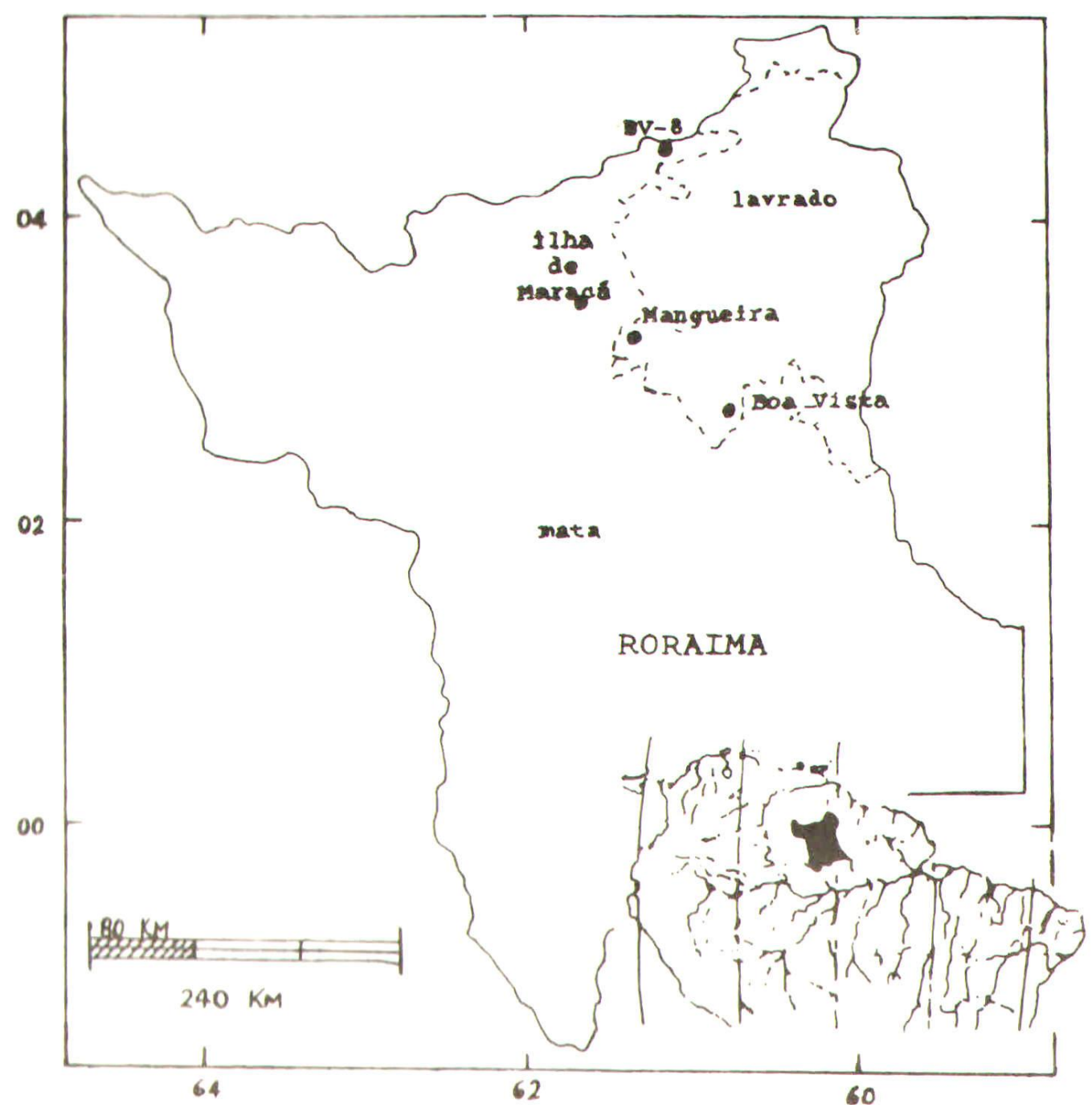

FIGURA 1: Região de Roraima com as localidades estudadas. (Adaptado de Vanzolini \& Carvalho, 1991)

\section{Análise taxonômica}

O método para identificação e análise taxonômica de serpentes é feito através de contagens de escamas, principalmente i) as fileiras dorsais, contadas em três regiões do corpo - ao nível do pescoço, meio do corpo e região anal, ii) número de escamas ventrais e número de subcaudais, procedimentos utilizados neste exercício (Clark \& Inger, 1942; Vanzolini et al., 1980).

Bol. Mus. Int. de Roraima, Boa Vista, 3 (1): 20-35, jul. 1995. 
As descrições estatísticas das distribuições de freqüências foram as usuais (teoria em Vanzolini, 1993): amplitude das variáveis, número de amostras, desvio de amostras, desvio da média, desvio padrão, coeficiente de variação e intervalo de confiança da média. Para as demais análises seguiu-se Vanzolini (1993) e Zar (1974).

Examinou-se 73 exemplares de L. annulata; as análises estatísticas das variações no número de escamas entre as localidades amostradas não foram significantes ao nível $\mathrm{P}<0,05$, bem como não foi significante a variação das escamas dorsais entre localidades de mata e lavrado.

\section{Escamas dorsais}

i) pescoço: as escamas foram contadas a cerca 5 centímetros da cabeça no sentido ântero-posterior. As escamas são em 18, 19, 20 e 21 fileiras, com incidência maior em 19 fileiras (92\% dos exemplares), nas quatro localidades e com proporções aproximadamente iguais entre exemplares da mata e lavrado - 37 e 30, respectivamente. Desviaram de 19 fileiras de escamas ao redor do pescoço, um número de 6 exemplares. Não foram necessários testes estatísticos para verificar as variações. As simples distribuições de freqüências mostraram as incidências (Tabelas 2 e 3 ).

TABELA 2. Escamas dorsais de Leptodeira annulata: Distribuições de freqüências por localidades

\begin{tabular}{|c|c|c|c|c|c|c|}
\hline & & Boa Vista & $\mathrm{BV}-8$ & Maracá & Mangueira & $\frac{\circ}{0}$ \\
\hline \multirow{5}{*}{ Pescoço } & 18 & 3 & - & - & - & 4,0 \\
\hline & 19 & 21 & 16 & 21 & 9 & 92,0 \\
\hline & 20 & 1 & - & - & - & 1,3 \\
\hline & 21 & - & - & - & 2 & 2,7 \\
\hline & soma & 25 & 16 & 21 & 11 & 100,0 \\
\hline \multirow{4}{*}{$\begin{array}{l}\text { Meio do } \\
\text { Corpo }\end{array}$} & 19 & 5 & 3 & 9 & 3 & $27,5^{1}$ \\
\hline & 20 & 2 & 1 & - & - & 4,0 \\
\hline & 21 & 18 & 12 & 12 & 8 & $68,5^{2}$ \\
\hline & soma & 25 & 16 & 21 & 11 & 100,0 \\
\hline \multirow{5}{*}{ Anais } & 14 & 1 & 1 & - & - & 3,0 \\
\hline & 15 & 14 & 12 & 20 & 11 & 78,0 \\
\hline & 16 & 3 & - & - & - & 4,0 \\
\hline & 17 & 7 & 3 & 1 & - & 15,0 \\
\hline & soma & 25 & 16 & 21 & 11 & 100,0 \\
\hline
\end{tabular}

1. Tipo I; 2. Tipo II.

Bol. Mus. Int. de Roraima, Boa Vista, 3 (1): 20-35, jul. 1995. 
ii) meio do corpo: as contagens das escamas foram feitas na região dorsal, correspondente à metade da distância entre a cabeça e o ânus. As escamas são em 19, 20 e 21 fileiras, nas quatro localidades, com incidências maiores em 19 (27,5\%) e 21 fileiras $(68,5 \%)$, que arbitrariamente chamei de tipos I (19) e II (21) (Tabela 2). Desviaram desses padrões um número de 3 exemplares. A proporção entre exemplares da mata e do lavrado com 19 fileiras de escamas ao meio do corpo, é de 12:8; com 21 fileiras, a proporção é de 24:26 exemplares (Tabela 3). Para verificar se essa variação poderia ser significante entre exemplares da mata e lavrado, foi aplicado o teste qui-quadrado. As localidades são homogêneas com relação ao número de escamas em 19 fileiras (Tipo I) e 20 fileiras (Tipo II), isto é, não há predominância de indivíduos com 19 ou 21 fileiras de escamas na mata ou no lavrado $\left(\mathrm{x}^{2}=0,251 ; \mathrm{g} .1 .=1 ; 0,50<\mathrm{P}<0,75\right.$; Tabela 4);

TABELA 3. Escamas dorsais de Leptodeira annulata do lavrado (Boa Vista e Maloca Mangueira) e mata (BV-8 e Maracá): Distribuições de freqüências

\begin{tabular}{|c|c|c|c|c|}
\hline & & Lavrado & Mata & Soma \\
\hline & 18 & 3 & - & 3 \\
\hline \multirow[t]{5}{*}{ Pescoço } & 19 & 30 & 37 & 67 \\
\hline & 20 & 1 & - & 1 \\
\hline & 21 & 2 & - & 2 \\
\hline & soma & 36 & 37 & 73 \\
\hline & 19 & 8 & 12 & 20 \\
\hline Meio do & 20 & 2 & 1 & 3 \\
\hline \multirow[t]{3}{*}{ Corpo } & 21 & 26 & 24 & 50 \\
\hline & soma & 36 & 37 & 73 \\
\hline & 14 & 1 & 1 & 2 \\
\hline \multirow[t]{4}{*}{ Anais } & 15 & 25 & 32 & 57 \\
\hline & 16 & 3 & - & 3 \\
\hline & 17 & 7 & 4 & 11 \\
\hline & soma & 36 & 37 & 73 \\
\hline
\end{tabular}

Bol. Mus. Int. de Roraima, Boa Vista, 3 (1): 20-35, jul. 1995. 
TABELA 4. Incidência no número de escamas dorsais de Leptodeira annulata em mata (BV-8 e Maracá) e lavrado (Boa Vista e Mangueira): Teste de Qui-quadrado

\begin{tabular}{|c|c|c|}
\hline & Tipo $I^{1}$ & Tipo $I I^{2}$ \\
\hline Lavrado & 8 & 26 \\
\hline Mata & 12 & 24 \\
\hline
\end{tabular}

1. 19 fileiras; 2. 21 fileiras.

$$
\begin{aligned}
& x=0,251 \\
& 9.1 .=1 \\
& 0,50<p<0,75
\end{aligned}
$$

iii) anais: as escamas foram contadas a um centímetro ou pouco mais da região que antecede o ânus. Estas escamas, como as da região do pescoço, não necessitaram de tratamento estatístico. As simples distribuições de freqüências das variações no número de escamas entre localidades, e nas localidades de mata e lavrado agrupadas mostraram incidências maiores (Tabelas 2 e 3). As escamas são reduzidas para 14, 15, 16 ou 17 fileiras. As incidências são em 15 fileiras (78\% dos exemplares) nas quatro localidades, e 17 fileiras de escamas (15\% dos exemplares) em três localidades - apenas Mangueira não apresentou escamas em 17 fileiras na região anal. A proporção de exemplares com 15 fileiras na mata e no lavrado é de 32:25, respectivamente; com 17 fileiras a proporção cai de 4:7 exemplares na mata e no lavrado. Desviaram desses padrões (15 e 17 fileiras) um número de 5 exemplares.

2. Escamas ventrais: as ventrais foram contadas a partir da primeira escama mais longa que larga posterior às post-mentais, até a escama que precede à anal. As ventrais variam de 167 a 201 entre as localidades (Tabela5).

Bol. Mus. Int. de Roraima, Boa Vista, 3 (1): 20-35, jul. 1995. 
TABELA 5. Escamas ventrais de Leptodeira annulata: Distribuições de freqüências por localidades

\begin{tabular}{|c|c|c|c|c|}
\hline & Boa Vista & $\mathrm{BV}-8$ & Maracá & Mangueira \\
\hline 167 & - & 1 & - & - \\
\hline 168 & - & - & - & - \\
\hline 169 & - & - & - & - \\
\hline 170 & - & - & - & - \\
\hline 171 & 1 & - & - & - \\
\hline 172 & - & - & - & - \\
\hline 173 & - & - & - & - \\
\hline 174 & - & - & - & - \\
\hline 175 & - & - & 2 & - \\
\hline 176 & 1 & - & - & 1 \\
\hline 177 & 2 & - & - & - \\
\hline 178 & 1 & 1 & - & - \\
\hline 179 & 1 & - & 1 & - \\
\hline 180 & 1 & - & - & - \\
\hline 181 & - & - & - & 1 \\
\hline 182 & 1 & - & - & - \\
\hline 183 & 3 & - & 1 & 1 \\
\hline 184 & 2 & - & - & - \\
\hline 185 & 4 & 1 & 3 & 3 \\
\hline 186 & 1 & - & 1 & 1 \\
\hline 187 & 1 & 3 & 3 & - \\
\hline 188 & 1 & 3 & 1 & 1 \\
\hline 189 & - & 1 & 2 & 1 \\
\hline 190 & 1 & 2 & 1 & 1 \\
\hline 191 & - & 2 & 1 & - \\
\hline 192 & 2 & 1 & 2 & - \\
\hline 193 & - & - & - & - \\
\hline 194 & 1 & 1 & - & - \\
\hline 195 & - & - & - & - \\
\hline 196 & 1 & - & - & 1 \\
\hline 197 & - & - & - & - \\
\hline 198 & - & - & - & - \\
\hline 199 & - & - & - & - \\
\hline 200 & - & - & - & - \\
\hline 201 & - & - & 2 & - \\
\hline soma & 25 & 16 & 20 & 11 \\
\hline
\end{tabular}

Bol. Mus. Int. de Roraima, Boa Vista, 3 (1): 20-35 jul. 1995. 
Os valores descritos na distribuição de freqüências entre localidades foram submetidos à análise de variância. As quatro localidades mostraram-se homogêneas com relação à variação observada nas ventrais ( $F=$ 1,$2619 ; \mathrm{F}_{0,05(1) 3,60}=2,76 ; \mathrm{P}<0,50 ;$ Tabela 6).

TABELA 6. Escamas ventrais de Leptodeira annulata: Estatísticas das distribuições de freqüências

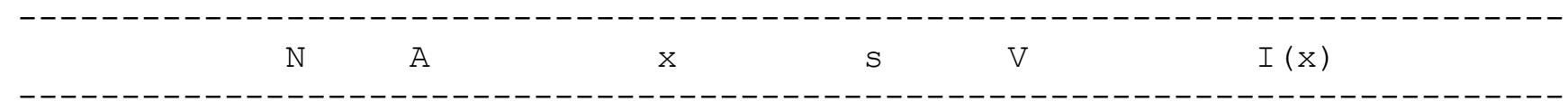

Boa Vista $25 \quad 171-196 \quad 184,08 \pm 1,980 \quad 5,97 \quad 3,2554 \quad 181,6063-186,5537$

BV-8 $\quad 16 \quad 167-194 \quad 187,0 \pm 1,602 \quad 6,40 \quad 3,4269 \quad 183,5829-190,4141$

Maracá $\quad 20 \quad 175-201 \quad 187,35 \pm 1,499 \quad 6,70 \quad 3,5790 \quad 184,2113-190,4887$

Mangueira $\quad 11 \quad 176-196 \quad 185,81 \pm 1,550 \quad 5,15 \quad 2,7700 \quad 184,2600-189,2634$

$\mathrm{N}=\mathrm{N}^{\circ}$ de amostras

$A=$ Amplitude

$\mathrm{x}$ = Média \pm Desvio padrão

$\mathrm{s}=$ Desvio padrão

$\mathrm{V}=$ Coeficiente de Variação

$I(x)=$ Intervalo de confiança da média

Análise de variância:

$F=1,2619$

$\mathrm{F}_{0,05(1) 3,60}=2,76$

$\mathrm{P}<0,50$

3. Escamas subcaudais: as subcaudais foram contadas a partir da primeira escama imediatamente posterior ao ânus, até a extremidade da cauda. Quando esta não é mutilada, é revestida por uma escama um pouco maior, cônica; não é fácil às vezes reconhecer uma cauda mutilada. As escamas subcaudais variam de 58 a 92 entre as localidades (Tabela 7).

Bol. Mus. Int. de Roraima, Boa Vista, 3 (1): 20-35, jul. 1995. 
TABELA 7. Escamas subcaudais de Leptodeira annulata: Distribuições de freqüências por localidades

\begin{tabular}{|c|c|c|c|c|}
\hline & Boa Vista & $\mathrm{BV}-8$ & Maracá & Mangueira \\
\hline 58 & 1 & - & - & - \\
\hline 59 & - & - & - & - \\
\hline 60 & - & - & - & - \\
\hline 61 & - & - & - & - \\
\hline 62 & - & - & - & - \\
\hline 63 & - & - & - & - \\
\hline 64 & 1 & - & - & - \\
\hline 65 & - & - & - & - \\
\hline 66 & - & - & - & - \\
\hline 67 & - & - & - & - \\
\hline 68 & - & - & 1 & - \\
\hline 69 & 3 & - & 1 & - \\
\hline 70 & - & - & - & - \\
\hline 71 & - & - & - & - \\
\hline 72 & - & - & - & - \\
\hline 73 & 1 & 1 & 1 & - \\
\hline 74 & 1 & - & - & - \\
\hline 75 & - & 1 & 1 & - \\
\hline 76 & 2 & 2 & - & 1 \\
\hline 77 & - & - & - & 1 \\
\hline 78 & 2 & 3 & 1 & - \\
\hline 79 & 1 & 3 & - & - \\
\hline 80 & 2 & - & 1 & 2 \\
\hline 81 & - & 1 & - & 1 \\
\hline 82 & 1 & - & - & - \\
\hline 83 & - & - & 2 & 1 \\
\hline 84 & 1 & 1 & 2 & - \\
\hline 85 & 1 & 1 & 6 & - \\
\hline 86 & 3 & - & - & - \\
\hline 87 & 1 & - & 3 & 1 \\
\hline 88 & 1 & - & - & - \\
\hline 89 & - & 1 & 1 & 1 \\
\hline 90 & - & - & - & - \\
\hline 91 & - & - & - & - \\
\hline 92 & - & - & - & 1 \\
\hline soma & 22 & 14 & 20 & 9 \\
\hline
\end{tabular}

Os valores descritos na distribuição de freqüências por localidades foram submetidos a análise de variância. As localidades mostraram-se homogêneas com relação a este caráter $\left(\mathrm{F}=2,1778 ; \mathrm{F}_{0,05(1) 3,60}=2,76\right.$; $0,10<\mathrm{P}<0,25 ;$ Tabela 8).

Bol. Mus. Int. de Roraima, Boa Vista, 3 (1): 20-35, jul. 1995. 
TABELA 8. Escamas subcaudais de Leptodeira annulata: Estatísticas das distribuições de freqüências

Boa Vista $22 \quad 58-88$
B
BV-8

Os resultados obtidos neste exercício indicaram que não houve diferenças significativas entre as médias dos parâmetros analisados. Em termos taxonômicos, isto quer dizer que as populações estudadas não diferem significativamente entre si.

Bol. Mus. Int. de Roraima, Boa Vista, 3 (1): 20-35, jul. 1995. 
As contagens de escamas dorsais, mais freqüentes em 19 e 21 fileiras ao meio do corpo caem dentro das variações citadas na literatura (Tabela 1), com exceção dos exemplares em 20 fileiras de Boa Vista (lavrado) e Vila Pacaraima (BV-8, mata). Considerou-se este desvio como sendo flutuações das amostras, mesmo porque o número de exemplares que apresentou esta contagem foi muito baixo. Existe o caso de contagens de 17 fileiras dorsais em L. annulata do Pará e outro com 15 fileiras (1 exemplar) da mesma região (Duellman, 1958), porém o número de exemplares analisados foi muito baixo e fica difícil qualquer comentário, mesmo porque no leste do Pará, Cunha \& Nascimento (1993, edição revisada de 1978) citam 19 e 21 fileiras normalmente encontradas nas escamas dorsais. Chippaux (1987) cita ainda um caso de 23 escamas dorsais encontrado na Guiana Francesa como sendo raro, normalmente as escamas são em 19 ou 21 fileiras dorsais, nos exemplares daquela região. Em resumo: a variação das fileiras de escamas dorsais ao meio do corpo parece ser normalmente em 19 ou 21 fileiras, como observado também na região de Roraima, onde, adicionalmente, não há predominância em 19 ou 21, na mata e no lavrado.

Com relação ao número de fileiras de escamas ao redor do pescoço e região anal, que mostrou incidências maiores em 19 e $15 / 17$ fileiras respectivamente, são mais difíceis de comparar com a literatura: pouca informação trazem sobre estas variações. Em serpentes é normal as escamas do pescoço e anais apresentarem um número de fileiras inferior ao meio do corpo, devido talvez às próprias características anatômicas. Porém, há exceções à regra - espécies da mesma família de L. annulata (Colubridae) e outras, em que o número de fileiras de escamas dorsais é constante, sem reduções. Como a maior parte dos exemplares de L. annulata anulados neste exercício apresentaram 15 fileiras de escamas na região anal (78\% dos exemplares), considerou-se os desvios observados de 14, 16 e 17 fileiras de escamas como sendo flutuações das amostras. Esses números são mais reduzidos ainda nos exemplares analisados por Duellman (1958) para os exemplares do baixo rio Amazonas, Pará: 11, 13, 15 e 17, porém como foi dito, baseados em poucos exemplares, o que dificulta qualquer comparação. Com relação às escamas da região do pescoço, estas variam muito pouco - 19 fileiras em 92\% dos indivíduos. Infelizmente não há nenhuma informação na literatura que possa ser comparada com os resultados encontrados nesta cobra em Roraima. Também considerou-se, com maior segurança ainda, os desvios observados no número de fileiras de escamas da região do pescoço, como sendo flutuações das amostras.

As variações nos números de escamas ventrais e subcaudais de $I$. annulata da região de Roraima caem folgadamente dentro das variações citadas na literatura. Alguns exemplares apresentaram um baixo número de subcaudais, quando comparados com as citações da literatura, mas foram extremos e em número muito baixo, não chegando a 1\% do total. Os exemplares da Guiana Francesa apresentam menos variações nas ventrais (Chippaux, 1987; Gasc \& Rodrigues, 1980).

Bol. Mus. Int. de Roraima, Boa Vista, 3 (1): 20-35, jul. 1995. 
Essa baixa variação nas ventrais nestes exemplares, juntamente com alguns indivíduos com 23 fileiras de escamas dorsais, podem ser muito relevantes na caracterização das populações ao norte da Amazônia. Mas, como a sistemática desta cobra é confusa, a nível em que este exercício foi realizado, não é possível avaliar corretamente essas diferenças e aprofundar a discussão. Isto demandaria outro tipo de estudo.

A homogeneidade das variações no número de escamas de L. annulata entre as localidades permite concluir que as populações das regiões estudadas freqüentam tanto a mata como o lavrado. Portanto, não estão ecologicamente isoladas.

Estas conclusões devem ser entendidas no sentido amplo e com as devidas cautelas que o caso merece. Embora não tenha havido violação nos conceitos biológicos, julgo apropriado fazer alguns comentários.

Primeiro: com relação a sistemática. Os caracteres a), número de escamas dorsais e b), número de escamas ventrais e subcaudais (e suas variações) utilizados neste exercício são atributos sem ambigüidades em serpentes e constatados em todos os indivíduos, porém, a conclusão de isolamento ecológico, utilizando-se apenas caracteres morfológicos como parâmetros, restringem o problema. Apenas detalhados e intensivos estudos ecológicos podem elucidar a estrutura especial e genética de uma espécie e, isto, mesmo em áreas restritas (Vanzolini, 1993, p.11).

Segundo: com relação aos ambientes e exemplares coletados. As áreas de mata das localidades estudadas estão situadas muito próximas às do lavrado, distribuídas em mosaicos e com muitas clareiras. Isto gerou uma certa imprecisão inarredável na caracterização dos exemplares de mata e lavrado, a maioria coletados nas bordas desses ambientes, ou pouco mais para o interior.

Finalmente, seguindo o mesmo raciocínio, poderia haver neste caso interpenetrações de indivíduos nos ambientes de coleta: um indivíduo coletado na mata pode na verdade pertencer a uma população que freqüenta o lavrado e vice-versa. Por exemplo, indivíduos de uma população que normalmente freqüenta o lavrado, eventualmente poderiam fazer incursões na mata, onde fosse acessível, mais aberta e em contato com o lavrado, porém estes dificilmente deveriam ser caracterizados como de mata. O inverso poderia também acontecer; em uma população que freqüentasse a mata até sua borda, alguns indivíduos eventualmente poderiam fazer incursões no lavrado onde este fosse perto da mata, digamos para se alimentar de anfíbios em algum lago - o alimento preferido de L. annulata. Estes indivíduos dificilmente também poderiam ser considerados como pertencentes ao lavrado. Como dito acima, seriam necessários estudos ecológicos detalhados para caracterizar firmemente estas situações, que são de extremo interesse biológico.

Bol. Mus. Int. de Roraima, Boa Vista, 3 (1): 20-35, jul. 1995. 
Entende-se que essa imprecisão não invalida este exercício, levanta outras possibilidades de estudo e fornece pistas que poderão ser fundamentais na caracterização ecológica das populações de L. annulata ao norte da Amazônia, considerando sempre o aspecto fisionômico de vegetação. Um estudo pormenorizado poderia revelar: i) distribuição contínua desta cobra na área de mata e áreas abertas e como sugerido preliminarmente pelos resultados deste exercício; ii) formas vicariantes em ambos ambientes mata e áreas abertas, com algumas interpenetrações de elementos na zona de simpatria, ou iii) um caso mais extremo, de populações separadas pela mata e lavrado, que este exercício não conseguiu detectar.

Apenas estudos comparativos mais minuciosos desta espécie poderão resolver estas questões teóricas, fundamentais no entendimento dos processos evolutivos e, além dos caracteres morfológicos, outras análises seriam desejáveis, como estudos de DNA mitocondrial e cromossomos das populações.

\section{BIBLIOGRAFIA}

-CLARK, J. P. \& INGER, R. Scale reduction snakes. [s.1.] Rev. Copeia. 1942 (3) : 163-170.

-CUNHA, O. R. \& NASCIMENTO, F. P. Ofídios de Roraima e notas sobre Erythrolamprus bauperthuisii, Duméril, Bibron \& Duméril. Bol. Mus. Para. Emílio Goeldi, sér. Zool., Belém, (102): 21, 1980.

-CUNHA, O. R. \& NASCIMENTO, F. P. Ofídios da Amazônia. As Cobras da Região Leste do Pará. Bol. Mus. Para. Emílio Goeldi, Sér. Zool., Belém, 9 (1) : 1-191, 1993.

-CHIPPAUX, J. P. Les serpents de la Guyane Française. Fauna tropicale XXVII. [S. l.] Inst. Français de Recherche scient. Pour le Développenent em Cooperation. 1987. 63 p.

-DUELLMAN, W. E. A monographic study of the Colubrid snake genus Leptodeira. Bull. Am. Mus. Nat. Hist. N. York, N. York, (114): 1-151, 1958 .

-GASC, J. P. \& RODRIGUES, M. T. Liste préliminire des serpents de la Guyane Française. Bull. Mus. Hist. Nat. Paris, Paris, A (2): 559-598, 1980.

-PETERS, J. A. \& OREJAS-MIRANDA, B. Catalogue of the neotropical squamata: Part I. Snakes. Revision Ed. (1970) withaddenda and corrigenda by VANzolinI, P. E. Washington, D. C. Smithisonian Inst. $26+$ VIII + 347 P. 1986 .

Bol. Mus. Int. de Roraima, Boa Vista, 3 (1): 20-35, jul. 1995. 
-ROZE, J. A. La taxonomia y zoogeografia de los ofídios en Venezuela: [s.l.] Ediciones de la Biblioteca. 1966. 169p.

-VAnZOlini, P. E.; RAMOS-COSTA, A. M. M. \& VITT, L. J. Répteis das Caatingas. Rio de Janeiro, Academia Brasileira de Ciências, 1980. 161 $\mathrm{p}$.

-VANZOLINI, P. E. \& CARVALHO, C. M. Two sibling and sympatric species of Gymnophtalmus in Roraima, Brasil (Sauria: Teiidae). Papéis Avulsos de Zoologia. [São Paulo] 37 (12): 173-226, 1991.

-VANZOLINI, P. E. Métodos estatísticos elementares em sistemática zoológica. São Paulo, Hucitec, 1993.

-ZAR, J. H. Biostatistical Analysis. New Jersey, Prentice-Hall Inc. 1974. $620 \mathrm{p}$. 